\title{
Moisture Retention and Chemical Properties of Nursery Potting Substrates ${ }^{1}$
}

\author{
Haimanote K. Bayabil, Fitsum T. Tilahun, Yuncong Li, and E. Vanessa Campoverde ${ }^{2}$
}

\section{Introduction}

Florida's nursery industry covers over 59,000 and 24,000 acres of container production and field-grown nursery plants, respectively, and it contributes considerably to the state's economy. In 2014, Florida nursery plant sales accounted for $\$ 1.8$ billion, and capital assets valued at $\$ 3.3$ billion (Hodges et al. 2016). Ornamental plants and commercial nursery plants are grown in containers or pots using potting media without natural soil (South Florida Gardening 2019). The chemical and physical properties of the substrates used in making the potting media influence the quality of the media and, in turn, the plant growth (Ingram 2014). Important physical characteristics of an ideal plant growth medium for container-grown plants include a good balance between the capacity of the medium to hold available water while maintaining adequate aeration (Raviv et al. 2002). Unlike soil, potting media hold a greater amount of water and nutrients. They can also easily release water and nutrients, so careful management is needed.

Potting medium is generally a mixture of different organicbased substrates with or without supplemental nutrients at the time of mixing to make it "ready to use" mix including nutrients. The proportion of different substrates in the mix can vary depending on the plant type, but generally, the mix is intended to provide optimal water and nutrient retention capacities.
The purpose of this publication is to provide general information about differences in moisture retention characteristics and chemical properties of most common potting substrates used by the nursery industry in south Florida. The information included in this document could be of interest to Extension agents, nursery growers, water managers, students, researchers, and the general public.

\section{Methods}

This document includes moisture retention characteristics and chemical and physical properties of selected nursery potting media substrates used in south Florida. The nursery substrates included two kinds of pine bark ( $3 / 4$ and $3 / 8$ size), Florida peat, hardwood, and coconut fiber, as well as one type of ready-to-use popular mix for comparison. The ready-to-use mix was prepared by mixing Florida peat, pine bark, and hardwood at $40 \%, 35 \%$, and $25 \%$ ratios, respectively.

Chemical analysis of these container media substrates was performed by the UF/IFAS Extension Testing Laboratory using the standard procedures described in Mylavarapu and Yeager (2018). The measurements included $\mathrm{pH}$, electrical conductivity (EC), and concentrations of $\mathrm{NO}_{3}-\mathrm{N}$, $\mathrm{P}, \mathrm{K}, \mathrm{Ca}$, and $\mathrm{Mg}$. Water retention of these materials was measured using the Bonsai test (https://www.youtube.com/ watch?v=Mt_a7g6C2Ls) (Figure 1).

1. This document is AE562, one of a series of the Department of Agricultural and Biological Engineering, UF/IFAS Extension. Original publication date October 2021. Visit the EDIS website at https://edis.ifas.ufl.edu for the currently supported version of this publication.

2. Haimanote K. Bayabil, assistant professor, Department of Agricultural and Biological Engineering, UF/IFAS Tropical Research and Education Center; Fitsum T. Tilahun, Ph.D. student, Department of Agricultural and Biological Engineering; Yuncong Li, professor, Department of Soil and Water Sciences, UF/IFAS Tropical Research and Education Center; and E. Vanessa Campoverde, Extension agent II, commercial agriculture/ornamentals, UF/IFAS Extension Miami-Dade County; UF/IFAS Extension, Gainesville, FL 32611.

The Institute of Food and Agricultural Sciences (IFAS) is an Equal Opportunity Institution authorized to provide research, educational information and other services

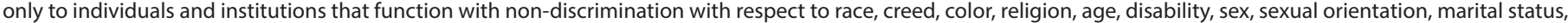

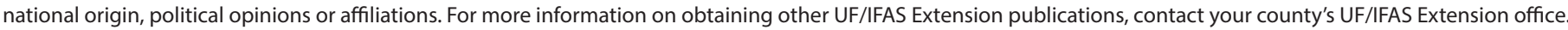
U.S. Department of Agriculture, UF/IFAS Extension Service, University of Florida, IFAS, Florida A \& M University Cooperative Extension Program, and Boards of County Commissioners Cooperating. Nick T. Place, dean for UF/IFAS Extension. 


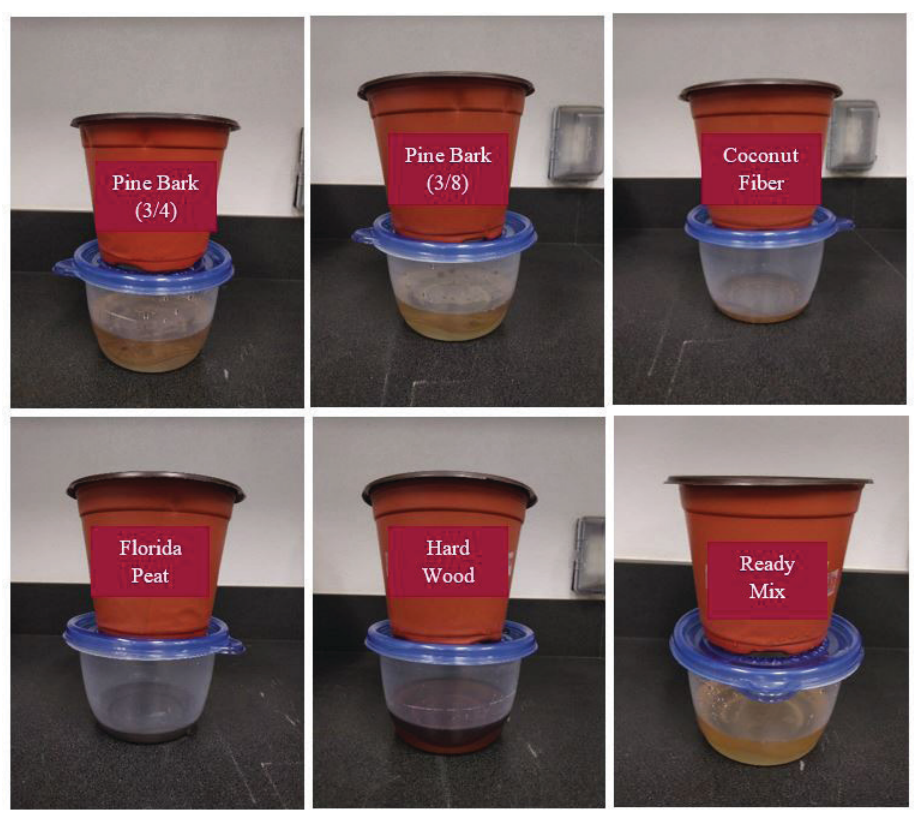

Figure 1. Bonsai test for water retention of six potting media used in south Florida.

Credits: H. K. Bayabil, UF/IFAS

Results in Table 1 show how much water a unit weight of dry potting substrate can hold. For example, one pound of dry coconut fiber can retain about 4 pounds of water, while one pound of dry Florida peat could hold about 0.81 pounds of water (Figure 2).

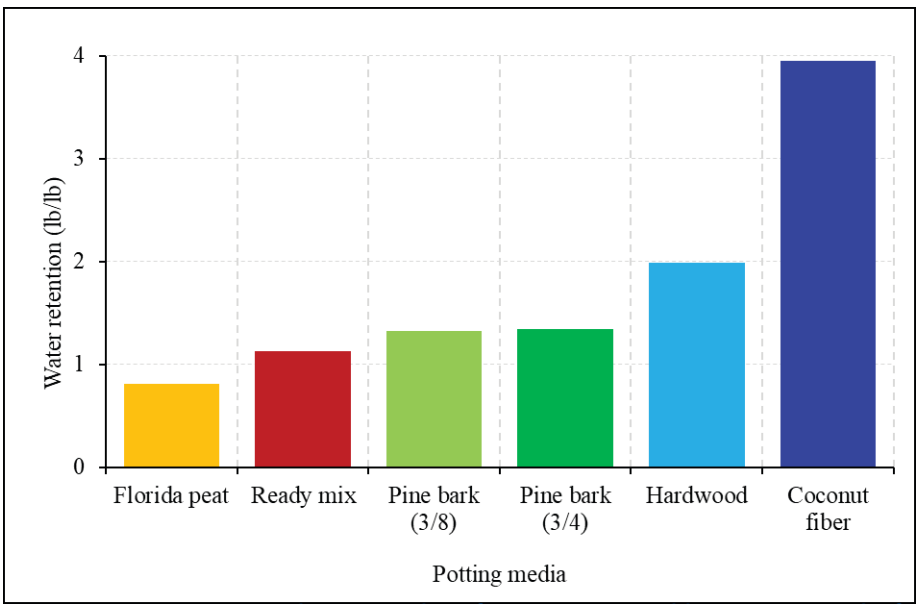

Figure 2. Average weight (pounds) of water retained by one pound of dry potting media.

Credits: H. K. Bayabil, UF/IFAS

Among the substrates, coconut fiber retained the highest water per dry weight basis (lb of water/ lb dry coconut fiber), followed by hardwood, pine bark, ready-mix, and Florida peat. Florida peat has very high organic matter content; therefore, it preserves a greater amount of water in air-dry status compared to the other substrates. This explains why water retention from the excess water added was lower in Florida peat than in the other substrates. However, total water retention of Florida peat was the highest.
The leachate $\mathrm{pH}$ varied from 6.31 to 7.95 for the substrates. Leachate $\mathrm{EC}$ is an indication of soluble nutrients in the substrate that are likely to leach. The leachate EC was high for Florida peat, hardwood, and ready-mix samples (Table 1). This is to be expected because these substrates have high organic matter and water-soluble nutrients; therefore, proper irrigation management is important to minimize nutrient leaching losses. On the other hand, pine bark is a very coarse, mostly fibrous substrate; therefore, it has a low amount of soluble nutrients compared to the rest of the substrates.

\section{Nutrients in Potting Substrates}

Optimal $\mathrm{pH}$ is a critical property of any medium for plant growth which influences the adequate availability of all nutrients. For most container media used for woody plants or bedding material for potted plants, the optimal $\mathrm{pH}$ is 5.5-5.8, while the acceptable $\mathrm{pH}$ is 5.0-5.6 (Mylavarapu et al. 2020). According to the above standards, the $\mathrm{pH}$ of pine bark was low. Hardwood and Florida peat had acceptable $\mathrm{pH}$, while coconut fiber and ready-mix had optimal $\mathrm{pH}$. The $\mathrm{pH}$ of the individual substrate is not that critical because the $\mathrm{pH}$ of the final potting mix depends on the proportion of different substrates used in the mix. Furthermore, the final $\mathrm{pH}$ of the potting media can be adjusted as needed. EC was high for Florida peat, followed by that for hardwood, ready-mix, coconut fiber, and pine bark. According to Mylavarapu et al. (2020), the ECs of all substrates evaluated were in the low range except for Florida peat (Tables 2 and 3). Nitrate-N represents readily available nitrogen in the liquid form. Florida peat has high $\mathrm{NO}_{3}-\mathrm{N}$, followed by ready-mix substrate. The rest of the substrates had trace amounts of $\mathrm{NO}_{3}-\mathrm{N}$ (i.e., less than 1 ppm). In most cases, plants grown in potting media must receive supplemental nutrients in either liquid or granular forms of fertilizer.

Phosphorus $(\mathrm{P})$ concentration was very high in hardwood, acceptable to optimal in pine bark and ready-mix, and low in Florida peat and coconut fiber substrates (Tables 2 and $3)$. Potassium $(\mathrm{K})$ was in the optimal to very high range for woody ornamentals in most substrates (Table 2). Concentrations of $\mathrm{K}$ were in the acceptable range for bedding and potted plants in ready-mix and coconut fiber, but low in pine bark and Florida peat (Table 3). Concentrations of Ca and $\mathrm{Mg}$ ranged from low to very high for woody plants; however, concentration levels of $\mathrm{Ca}$ and $\mathrm{Mg}$ for bedding and potted plants were low in all substrates except Florida peat, which has acceptable levels of $\mathrm{Ca}$ and $\mathrm{Mg}$. 


\section{Summary}

As the nursery industry thrives in south Florida, the use of potting substrates will also significantly increase. This publication provides general information about differences in moisture retention characteristics and chemical properties of the most common potting substrates used by the nursery industry in south Florida. The information included in this document will provide some insights into the different properties of potting substrates and the way the mixing ratio of these substrates affects moisture retention and other chemical properties. Different plants have different nutritional requirements and water needs, and potting substrates need to be prepared to meet plants' needs. Therefore, having a better understanding of the moisture retention, chemical properties, and nutrient contents is critical in order to better manage resources, including irrigation and fertilizer, for optimal plant growth and quality. Unlike south Florida soils, the potting media could hold a greater amount of water and nutrients, but it could also release them easily, based on the composition of the media elements. Reference values for tested parameters are also included based on the standards of the UF/IFAS Extension Soil Testing Laboratory. These reference values were compared with readings of each parameter for each potting medium.

\section{Acknowledgments}

The authors would like to thank Eddie Vallin Soils in Homestead, Florida for providing the potting substrates used in this study.

\section{References}

Haynes, J., J. McLaughlin, L. Vasquez, and A. Hunsberger. 2018. "Low-Maintenance Landscape Plants for South Florida.” UF/IFAS Extension. Accessed on April 27, 2020. https://sfyl.ifas.ufl.edu/miami-dade/landscapes--gardening/ low-maintenance-landscape-plants-for-south-florida/

Hodges, A.W., H. Khachatryan, M. Rahmani, and C. D. Court. 2016. "Economic Contributions of the Environmental Horticulture Industry in Florida in 2015." UF/IFAS Food and Resource Economics Department. https://fred.ifas.ufl. edu/pdf/EconContEnvirHortIndFL2015-11-15-16.pdf

Ingram, D. L. 2014. "Understanding Soilless Media Test Results and Their Implications on Nursery and Greenhouse Crop Management." University of Kentucky College of Agriculture, Food and Environment HO-112 Cooperative Extension Service 4.
Massey, H. F., J. P. Chastain, T. O. Owino, R. F. Polomski, and K. Moore. 2011. "Chemical and Physical Properties of Potting Media Containing Varying Amounts of Composted Poultry Litter." In ASABE Meeting Presentation. 20.

Mylavarapu, R., J. Bergeron, and N. Wilkinson. 2020. "Interpretation of Container Media Test Results. Florida Cooperative Extension Services.” UF/IFAS Analytical Services Laboratories, Extension Soil Testing Laboratory. January 15, 2020.

Mylavarapu, R., and T. Yeager. 2018. UF/IFAS Extension Nutrient Management Series: Container Media Nutrient Test Interpretation. SL180. Gainesville: University of Florida Institute of Food and Agricultural Sciences. https://edis.ifas. ufl.edu/ss316

Raviv, M., R. Wallach, A. Silber, and A. D. Bar-Tal. 2002. "Substrates and Their Analysis." In Hydroponic Production of Vegetables and Ornamentals. 25-105.

South Florida Gardening. 2019. "Preparing the Soil - Update. South Florida Gardening." South Florida Gardening. Accessed on April 27, 2020. http://www.soflagardening. com/preparing-soil-update/ 
Table 1. Moisture retention, and chemical properties of leachate from potting substrates.

\begin{tabular}{|l|c|c|}
\hline \multirow{2}{*}{ Substrate } & Water Retention & EC \\
\hline Hardwood & $\mathbf{( \% )}$ & (dS/cm) \\
\hline Pine bark (3/4) & 199 & 9.9 \\
\hline Pine bark (3/8) & 134 & 4.9 \\
\hline Florida peat & 132 & 5.5 \\
\hline Coconut fiber & 81 & 9.9 \\
\hline Ready-mix & 395 & 8.1 \\
\hline
\end{tabular}

Table 2. Chemical properties of the potting substrates and interpretation of results for woody ornamentals based on UF/IFAS Extension Soil Testing Laboratory guidelines (Mylavarapu et al. 2020).

\begin{tabular}{|c|c|c|c|c|c|c|c|}
\hline \multirow[t]{2}{*}{ Substrate } & pH & EC & $\mathrm{NO}_{3}-\mathrm{N}$ & $\mathbf{P}$ & K & $\mathrm{Ca}$ & Mg \\
\hline & & $(\mathrm{dS} / \mathrm{cm})$ & \multicolumn{5}{|c|}{ 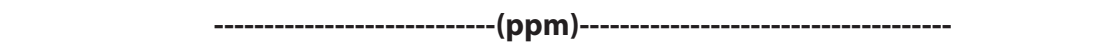 } \\
\hline \multirow[t]{2}{*}{ Hardwood } & 5.49 & 0.68 & 0.12 & 63.73 & 180.65 & 14.72 & 6.4 \\
\hline & (Acceptable) & (Low) & (Low) & (V. High) & (V. High) & (Acceptable) & (Low) \\
\hline \multirow[t]{2}{*}{ Pine bark (3/4) } & 4.46 & 0.19 & 0.18 & 3.93 & 37.84 & 6.6 & 2.52 \\
\hline & (Low) & (Low) & (Low) & (Acceptable) & (Optimum) & (Low) & (Low) \\
\hline \multirow[t]{2}{*}{ Pine bark (3/8) } & 4.53 & 0.22 & 0.11 & 6.03 & 40.32 & 7.28 & 2.75 \\
\hline & (Low) & (Low) & (Low) & (Acceptable) & (High) & (Low) & (Low) \\
\hline \multirow[t]{2}{*}{ Florida peat } & 5.45 & 1.22 & 32.91 & 0.31 & 31.22 & 118.64 & 39.01 \\
\hline & (Acceptable) & (Optimum) & (Low) & (Low) & (Optimum) & (V. High) & (High) \\
\hline \multirow[t]{2}{*}{ Coconut fiber } & 6.21 & 0.3 & 0.25 & 2.75 & 62.82 & 2.33 & 0.86 \\
\hline & (High) & (Low) & (Low) & (Low) & (High) & (Low) & (Low) \\
\hline \multirow[t]{2}{*}{ Ready-mix } & 6.37 & 0.63 & 15.45 & 3.23 & 89.16 & 24.88 & 13.99 \\
\hline & (High) & (Low) & (Low) & (Acceptable) & (V. High) & (Optimum) & (Acceptable) \\
\hline
\end{tabular}

Table 3. Chemical properties of the potting substrates and interpretation of results for bedding and potted plants based on UF/ IFAS Extension Soil Testing Laboratory guidelines (Mylavarapu et al. 2020).

\begin{tabular}{|c|c|c|c|c|c|c|c|}
\hline \multirow[t]{2}{*}{ Substrate } & pH & EC & $\mathrm{NO}_{3}-\mathrm{N}$ & $\mathbf{P}$ & K & $\mathrm{Ca}$ & Mg \\
\hline & & $(\mathrm{dS} / \mathrm{cm})$ & \multicolumn{5}{|c|}{ 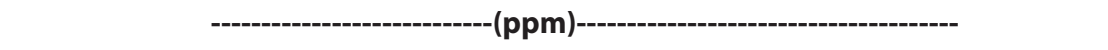 } \\
\hline \multirow[t]{2}{*}{ Hardwood } & 5.49 & 0.68 & 0.12 & 63.73 & 180.65 & 14.72 & 6.4 \\
\hline & (Acceptable) & (Low) & (Low) & (V. High) & (Optimum) & (Low) & (Low) \\
\hline \multirow[t]{2}{*}{ Pine bark (3/4) } & 4.46 & 0.19 & 0.18 & 3.93 & 37.84 & 6.6 & 2.52 \\
\hline & (Low) & (Low) & (Low) & (Acceptable) & (Low) & (Low) & (Low) \\
\hline \multirow[t]{2}{*}{ Pine bark (3/8) } & 4.53 & 0.22 & 0.11 & 6.03 & 40.32 & 7.28 & 2.75 \\
\hline & (Low) & (Low) & (Low) & (Optimum) & (Low) & (Low) & (Low) \\
\hline \multirow[t]{2}{*}{ Florida peat } & 5.45 & 1.22 & 32.91 & 0.31 & 31.22 & 118.64 & 39.01 \\
\hline & (Acceptable) & (Acceptable) & (Low) & (Low) & (Low) & (Acceptable) & (Acceptable) \\
\hline \multirow[t]{2}{*}{ Coconut fiber } & 6.21 & 0.3 & 0.25 & 2.75 & 62.82 & 2.33 & 0.86 \\
\hline & (High) & (Low) & (Low) & (Low) & (Acceptable) & (Low) & (Low) \\
\hline \multirow[t]{2}{*}{ Ready-mix } & 6.37 & 0.63 & 15.45 & 3.23 & 89.16 & 24.88 & 13.99 \\
\hline & (High) & (Low) & (Low) & (Acceptable) & (Acceptable) & (Low) & (Low) \\
\hline
\end{tabular}

